Cont rol I ed radical pol ymerizat i on wi th pol yol ef i n macroi ni ti at or : a conveni ent and versat i le approach to pol yol ef i $n$-based bl ock and graft copol ymers

\begin{tabular}{|l|l|}
\hline 著者 & $\begin{array}{l}\text { Sugi mot o Ryui chi, Kaneko Hi deyuki, Sai to } \\
\text { Junj i , Kawahar a Nobuo, Nat suo Shi ngo, Nat sugi } \\
\text { Tonmaki }\end{array}$ \\
\hline $\begin{array}{l}\text { j our nal or } \\
\text { publ i cat i on t i t e }\end{array}$ & Pol ymer Bul I et i n \\
\hline vol une & 71 \\
\hline number & 6 \\
\hline page r ange & $1421-1431$ \\
\hline year & $2014-06$ \\
\hline URL & ht t p: //hdl . handl e. net /10173/1453 \\
\hline
\end{tabular}




\title{
Controlled Radical Polymerization with Polyolefin Macroinitiator: A Convenient and Versatile Approach to Polyolefin-based Block and Graft Copolymers
}

Ryuichi Sugimoto*, Hideyuki Kaneko, Junji Saito, Nobuo Kawahara, Shingo Matsuo and Tomoaki Matsugi

\author{
Ryuichi Sugimoto* \\ School of Environmental Science and Engineering, Kochi University of Technology, \\ Miyanokuchi, Tosayamada, Kami, Kochi 782-8502, Japan \\ Hideyuki Kaneko, Junji Saito, Nobuo Kawahara, Shingo Matsuo, Tomoaki Matsugi \\ Research Center, Mitsui Chemicals, Inc., 580-32 Nagaura, Sodegaura, Chiba 299-0265, Japan \\ E-mail: Sugimoto.Ryuichi@kochi-tech.ac.jp
}

\section{(Abstract)}

This paper introduces the new synthetic methodology of polyolefin-based block and graft copolymers with polar segments (e.g., polystyrene and poly(meth)acrylates). Various brominated polyolefins were prepared by bromination of polyolefins with $\mathrm{N}$-bromosccinimide. The resulting brominated polyolefins were able to initiate the controlled radical polymerization of polar monomers, such as methyl methacrylate, ethyl acrylate, $t$-butyl acrylate, styrene and 2-(dimethylamino)ethyl acrylate, by using a $\mathrm{CuBr} / N, N, N^{\prime}, N^{\prime \prime}, N^{\prime \prime}$-pentamethyldiethylenetriamine catalyst system, leading to a variety of polyolefin-based copolymers with a different content of the corresponding polar segment. Because of the accessible synthesis of polyolefin macroinitiators, this synthetic methodology is expected to result in the preparation of a wide range of polyolefin-based block and graft copolymers.

Keywords: atom transfer radical polymerization (ATRP); functionalization of polymers; graft polymers; halogenated; polyolefin

\section{Introduction}

Creation of functionalized polyolefins with designed topologies and compositions is one of the important and challenging themes in research and development of polyolefin materials. The presence of 
functional groups on the polyolefin chains gives non-polar polyolefins enhanced properties, such as stiffness, toughness, adhesiveness, hydrophilicity, barrier properties and compatibility with other polar polymers.[1-3] One topic of interest in this area is the development of polyolefin-based block and graft copolymers linked between polyolefin and polar segments (e.g., polystyrene and poly(meth)acrylates).[4-8] Although each constituting polymer segment in such copolymers is generally immiscible, a covalent chemical linkage between them is expected to realize novel value-added polyolefin materials with a variety of bulk microstructures giving rise to thermoplastic elastomers, compatibilizers and impact modifiers.

From an industrial point of view, the grafting methods of the polar segments by radical reaction or ionizing radiation (X-ray, $\gamma$-ray and electron beam) are well known as a useful method for the syntheses of polyolefin-based copolymers. However, it has been difficult to obtain the well-defined polymer structures because the radical species formed by a hydrogen abstraction from the polyolefin backbone is less stable and cannot control the initiation and chain propagation reactions on the graft polymerization of the polar monomers. To overcome this problem, there have recently been many reports on the syntheses of the polyolefin-based copolymers by living polymerization with the functionalized polyolefins possessing suitable initiation sites. In particular, metal-catalyzed living (or atom transfer) radical polymerization[9-10] with a polyolefin macroinitiator, possessing active carbon-halogen bond(s) on its backbone, is one of the most successful methods for realizing a well-defined polymer architecture. Such polyolefin macroinitiators can be generally prepared by a multiple-step reaction consisting of preparing the functionalized polyolefin with reactive groups, such as hydroxyl,[11-14] glycidyl,[15] phenyl[16-18] and maleic anhydride group,[19] and subsequently their transformation into the initiation site. However, most of the functionalized polyolefins were prepared under unusual olefin polymerization conditions in the presence of specific chain transfer agents or polar monomers, which are poisonous for most olefin polymerization catalysts to retard the polymerization. 


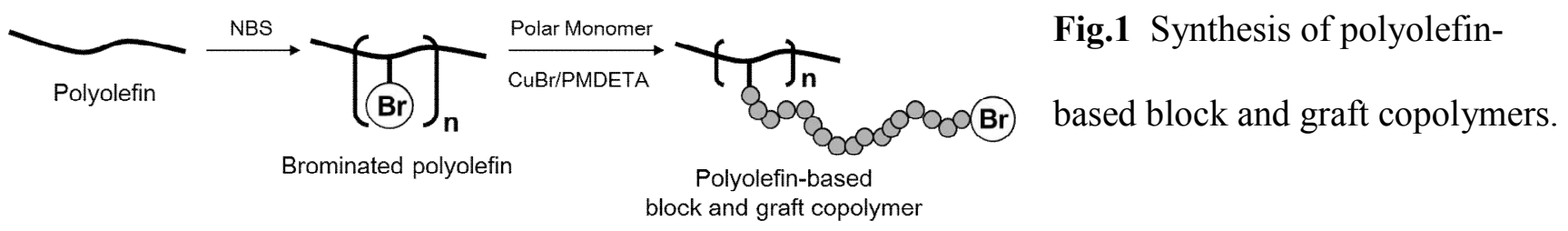

On the other hand, we previously reported that a terminal vinylidene group in isotactic polypropylene (PP) was selectively brominated by $N$-bromosuccinimide (NBS) to give the allylic bromide moiety. The thus obtained brominated PP was able to be used as a macroinitiator for metal-catalyzed living radical polymerization to give PP-based block copolymers linking polystyrene, poly(methyl methacrylate) and poly(n-butyl acrylate).[20] In this communication, as shown in Figure 1, we would like to demonstrate how this direct bromination method can be universally utilized for many commercially available polyolefins with or without unsaturated groups to produce polyolefin macroinitiators so that subsequently the thus obtained macroinitiators enable to create a variety of polyolefin-based block and graft copolymers with polar segments.

\section{Experimental Section}

\section{Materials}

All manipulations of air- and water-sensitive materials were performed under a dry nitrogen atmosphere in a conventional nitrogen-filled glove box. $\mathrm{N}$-bromosuccinimide (NBS), chlorobenzene, $\mathrm{CuBr}$ and $N, N, N$ ', $N$ ', $N$ ' '-pentamethyldiethylenetriamine (PMDETA) were purchased from Wako Pure Chemical Industries and used without further purification. Methyl methacrylate (MMA), ethyl acrylate (EA), $t$ butyl acrylate (tBA), styrene (St) and dimethylaminoethyl acrylate (DMAEA) (Wako Pure Chemical Industries) were dried over $\mathrm{CaH}_{2}$ and distilled in vacuo. o-Xylene used as a solvent were dried over $\mathrm{Al}_{2} \mathrm{O}_{3}$ and degassed by bubbling with $\mathrm{N}_{2}$ gas. Commercially-available polyolefins were used in this work: PP (Prime Polypro ${ }^{\mathrm{TM}}$ S119, Prime Polymer), HDPE (HI-ZEX ${ }^{\mathrm{TM}}$ 2200J, Prime Polymer), LDPE (MILASON $^{\mathrm{TM}} 11 \mathrm{P}$, Mitsui Chemicals. Inc.), LLDPE (NEO-ZEX ${ }^{\mathrm{TM}}$ 2540R, Prime Polymer), PMP (TPX ${ }^{\circledR}$ DX820, Mitsui Chemicals, Inc.), EP (TAFMER ${ }^{\mathrm{TM}}$ P-0080K, Mitsui Chemicals, Inc.) and EB (TAFMER $^{\mathrm{TM}}$ A-0550S, Mitsui Chemicals, Inc.). 


\section{Analytical Procedures}

${ }^{1} \mathrm{H}$ NMR spectra were recorded on JEOL GSX-400 (400 MHz) spectrometers using 1,2dichlorobenzene- $d_{4}$ as a solvent at $120{ }^{\circ} \mathrm{C}$. The gel permeation chromatograms calibrated with PP, PE or EPR were recorded by using a Waters Alliance GPC2000 equipped with four TSKgel columns (two sets of TSKgelGMH ${ }_{6}-\mathrm{HT}$ and two sets of TSKgelGMH ${ }_{6}-\mathrm{HTL}$ ) and a refractive index detector at $140{ }^{\circ} \mathrm{C}$ in 1,2-dichlorobenzene and those calibrated with PS standard were recorded by using a CFC T-150A (Mitsubishi Kagaku Corp.) equipped with three columns (Shodex AT-806MS) and an IR spectrometer Miran $1 \mathrm{ACVF}$ at $140{ }^{\circ} \mathrm{C}$ in 1,2-dichlorobenzene. Differential scanning calorimetry (DSC) was measured on a Seiko Instruments RDC220 differential scanning calorimeter. The DSC curves were recorded during the second heating cycle from 30 to $230{ }^{\circ} \mathrm{C}$ for the homo PP and brominated PP and -100 to 230 ${ }^{\circ} \mathrm{C}$ for the copolymers, with a heating rate of $10{ }^{\circ} \mathrm{C} \mathrm{min}^{-1}$.

\section{Bromination of Polyolefin}

A typical process is as follows (entry 2 in Table 1$)$ : Chlorobenzene $(1500 \mathrm{~mL})$ and PP pellet $(75 \mathrm{~g})$ were placed in a 2-L glass reactor equipped with a mechanical stir bar and then PP pellet was dissolved at 120 ${ }^{\circ} \mathrm{C}$ for $2 \mathrm{~h}$ under nitrogen atmosphere. After cooling to $100{ }^{\circ} \mathrm{C}$, NBS $(1.67 \mathrm{~g}, 10.6 \mathrm{mmol})$ was added and the mixture was maintained at $100{ }^{\circ} \mathrm{C}$ for $2 \mathrm{~h}$ under stirring. Then, the reaction mixture was cooled to ambient temperatures under stirring and the obtained slurry was poured into $3 \mathrm{~L}$ of acetone. The precipitated polymer was collected by filtration, washed with acetone and dried in vacuo at $80{ }^{\circ} \mathrm{C}$ for 10 $\mathrm{h}$ to give $73.2 \mathrm{~g}$ of brominated PP (PP-Br) as a white powder. As shown in Table 1, ten kinds of brominated polyolefins were obtained.

\section{Radical Polymerization of Polar Monomers with Brominated Polyolefin}

A typical polymerization process is as follows: PP- $\mathrm{Br}$ (2) (20 g, $1.08 \mathrm{mmol}$ as a bromine atom), MMA $(46 \mathrm{~mL})$ and $o$-xylene $(254 \mathrm{~mL})$ were placed in a $500 \mathrm{ml}$ glass reactor equipped with a mechanical stir bar and then this slurry was stirred at ambient temperatures for $2 \mathrm{~h}$ under nitrogen atmosphere. After adding a solution of $\mathrm{CuBr} / \mathrm{PMDETA}$ in $o$-xylene $(2.1 \mathrm{mmol}$ as a copper atom and $4.2 \mathrm{mmol}$ as PMDETA, pretreated for $5 \mathrm{~min}$.), the mixture was heated to $100{ }^{\circ} \mathrm{C}$ to dissolve $\mathrm{PP}-\mathrm{Br}$ and start the polymerization. Then, the reaction mixture was maintained at $100{ }^{\circ} \mathrm{C}$ for the prescribed times under 
stirring. The reaction mixture was cooled to ambient temperatures under stirring and the obtained slurry was poured into $1.5 \mathrm{~L}$ of methanol. The white powder was collected by filtration, washed with methanol and dried in vacuo at $80{ }^{\circ} \mathrm{C}$ for $10 \mathrm{~h}$. As shown later in Table 2 and 3, eleven kinds of copolymers were obtained.

\section{Results and Discussion}

Polyolefin macroinitiators were prepared by a bromination reaction of polyolefins. Some polyolefin products, such as PP, high-density polyethylene (HDPE), low-density polyethylene (LDPE), linear lowdensity polyethylene (LLDPE), poly(4-methyl-1-pentene) (PMP), ethylene/propylene copolymer (EP; propylene content $=20 \mathrm{~mol} \%)$ and ethylene/1-butene copolymer $(\mathrm{EB} ; 1$-butene content $=18 \mathrm{~mol} \%)$, were dissolved in chlorobenzene and brominated by NBS at $100{ }^{\circ} \mathrm{C}$ to prepare the corresponding brominated polyolefins. Table 1 shows the results of the bromination reaction of polyolefins. In the bromination reaction of PP (entries 1-4), the bromine content that was determined by ion chromatography, increased with increasing the feed ratio of NBS to PP, while the molecular weight decreased gradually, as shown in Figure 2. Moreover, average numbers of bromine can be determined to be 1.0-4.8 per chain from the number-average molecular weight $(\mathrm{Mn})$ and bromine content.

Table 1 Results of Bromination Reaction for Various Polyolefins with NBS

\begin{tabular}{|c|c|c|c|c|c|c|c|c|c|c|}
\hline \multirow[b]{2}{*}{ Entry $^{a}$} & \multirow[b]{2}{*}{$\mathrm{PO}$} & \multirow[b]{2}{*}{$\mathrm{NBS}^{\mathrm{b})}$} & \multicolumn{3}{|c|}{ before bromination } & \multicolumn{5}{|c|}{ after bromination } \\
\hline & & & $M_{\mathrm{n}}^{\mathrm{c})}$ & $\mathrm{PDI}^{\mathrm{c})}$ & $\begin{array}{c}T_{\mathrm{m}} \\
{\left[{ }^{\circ} \mathrm{C}\right]^{\mathrm{d})}}\end{array}$ & $M_{\mathrm{n}}^{\mathrm{c})}$ & $\mathrm{PDI}^{\mathrm{c})}$ & $\begin{array}{c}T_{\mathrm{m}} \\
{\left[{ }^{\circ} \mathrm{C}\right]^{\mathrm{d})}}\end{array}$ & $\begin{array}{c}\text { Br content } \\
{[\mathrm{wt} . \%]^{\mathrm{e})}}\end{array}$ & Br Number ${ }^{\mathrm{f}}$ \\
\hline 1 & $\mathrm{PP}$ & 0.01 & 52.4 & 2.4 & 164.4 & 48.9 & 2.5 & 154.4 & 0.17 & 1.0 \\
\hline 2 & PP & 0.025 & 52.4 & 2.4 & 164.4 & 41.4 & 2.5 & 151.7 & 0.43 & 2.2 \\
\hline 3 & PP & 0.05 & 52.4 & 2.4 & 164.4 & 30.8 & 2.2 & 147.6 & 1.0 & 3.9 \\
\hline 4 & PP & 0.1 & 52.4 & 2.4 & 164.4 & 19.0 & 2.0 & 142.5 & 2.0 & 4.8 \\
\hline 5 & PMP & 0.02 & 89.1 & 2.8 & 237.0 & 73.2 & 2.8 & 223.0 & 0.36 & 3.3 \\
\hline 6 & EP & 0.04 & 31.0 & 1.8 & 33.8 & 24.9 & 1.9 & 34.9 & 0.57 & 1.8 \\
\hline 7 & EB & 0.02 & 131.0 & 2.2 & 35.7 & 79.8 & 2.3 & 40.0 & 0.33 & 3.3 \\
\hline 8 & HDPE & 0.04 & 13.5 & 7.9 & 134.5 & 13.3 & 7.8 & 131.0 & 0.83 & 1.4 \\
\hline 9 & LDPE & 0.04 & 17.7 & 10.4 & 105.7 & 16.8 & 8.0 & 104.4 & 1.1 & 2.3 \\
\hline 10 & LLDPE & 0.04 & 23.9 & 3.4 & 118.8 & 22.9 & 2.9 & 116.9 & 1.2 & 3.4 \\
\hline
\end{tabular}



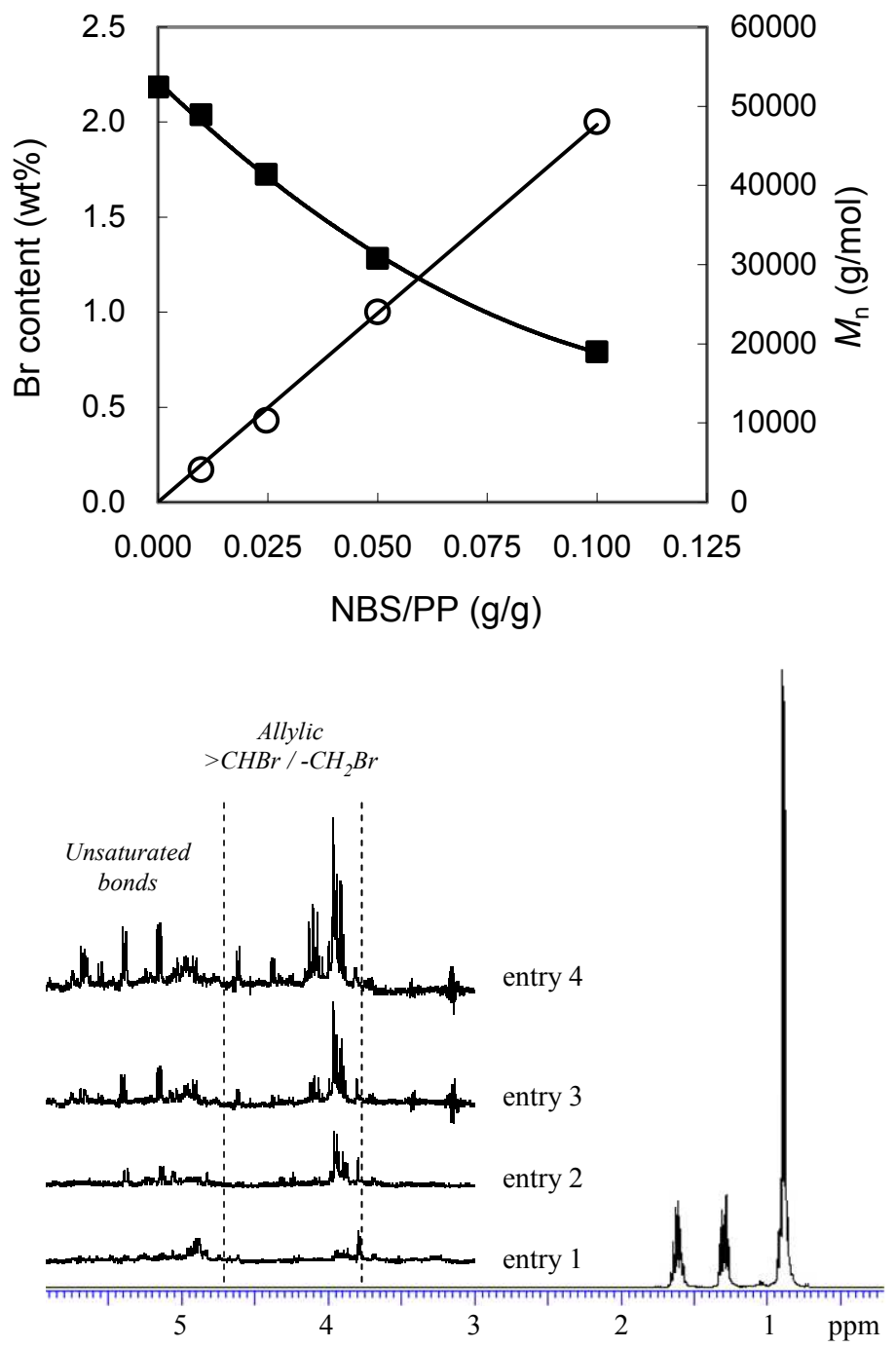

Fig.2 Plot of $\mathrm{Br}$ content and $\mathrm{Mn}$ of $\mathrm{PP}-\mathrm{Br}$ vs NBS/PP ratio.

Fig.3 ${ }^{1}$ H NMR spectra of the brominated PPs.

From ${ }^{1} \mathrm{H}$ NMR analysis, the protons of the allylic position and the unsaturated bonds were observed at $\delta$ 3.7-4.7 and 4.7-5.9 ppm as shown in Figure 3. These complicated signals revealed that several kinds of allylic bromide moieties were produced and their amounts can be increased with the increase of NBS feed ratio.

Figure 4 shows a plausible scheme concerning the bromination reaction. Bromine radicals generated from NBS attack the PP chain to produce the PP macroradical and then the obtained macroradical is transformed into the terminally- or inner-unsaturated structures. These unsaturated structures can be brominated to give many kinds of allylic bromide moieties. On the other hand, macroradicals are also directly brominated to give the tertiary or secondary bromide structures. The decrease of molecular 
weight after bromination suggests that the formation of terminally-brominated structures via the $\beta$ scission of the macroradical predominantly occurred. Similarly to PP, the bromination of other polyolefins was successfully carried out to give the corresponding brominated polyolefins (Table 1, entries 5-10). It is well known that the radical reaction of the polyolefins with high $\alpha$-olefin content are subject to degradation caused by the $\beta$-scission at a tertiary position of their macroradicals, whereas the polyolefins with low or no $\alpha$-olefin content, by contrast, are prone to branching or crosslinking caused by radical coupling between their macroradicals.[1]

Even in this study, the molecular weight of the polymers with high $\alpha$-olefin content (PMP, EP and EB; Table 1, entries 5-7) significantly decreased after bromination and the allylic bromide moieties formed through the $\beta$-scission mechanism as with PP. In the case of polyethylenes (Table1, entries $8-10$ ), the decrease of molecular weight was slight and a high molecular weight tailing was not observed, suggesting that degradation, branching and crosslinking basically did not occur at least in these reaction conditions. Furthermore, the major brominated structure in these brominated polyethylenes was not an allylic bromide but a secondary bromide as shown in Figure 5.

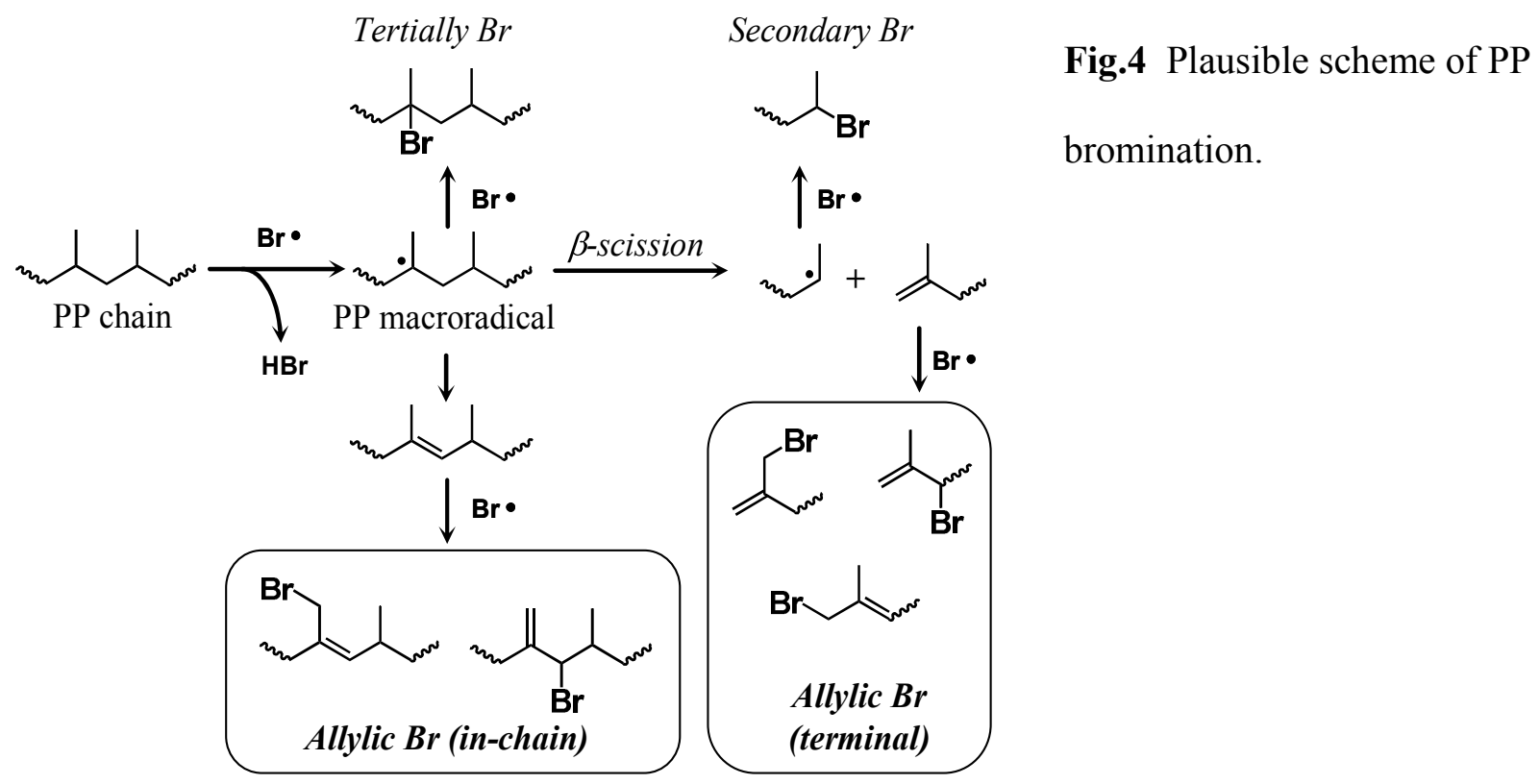




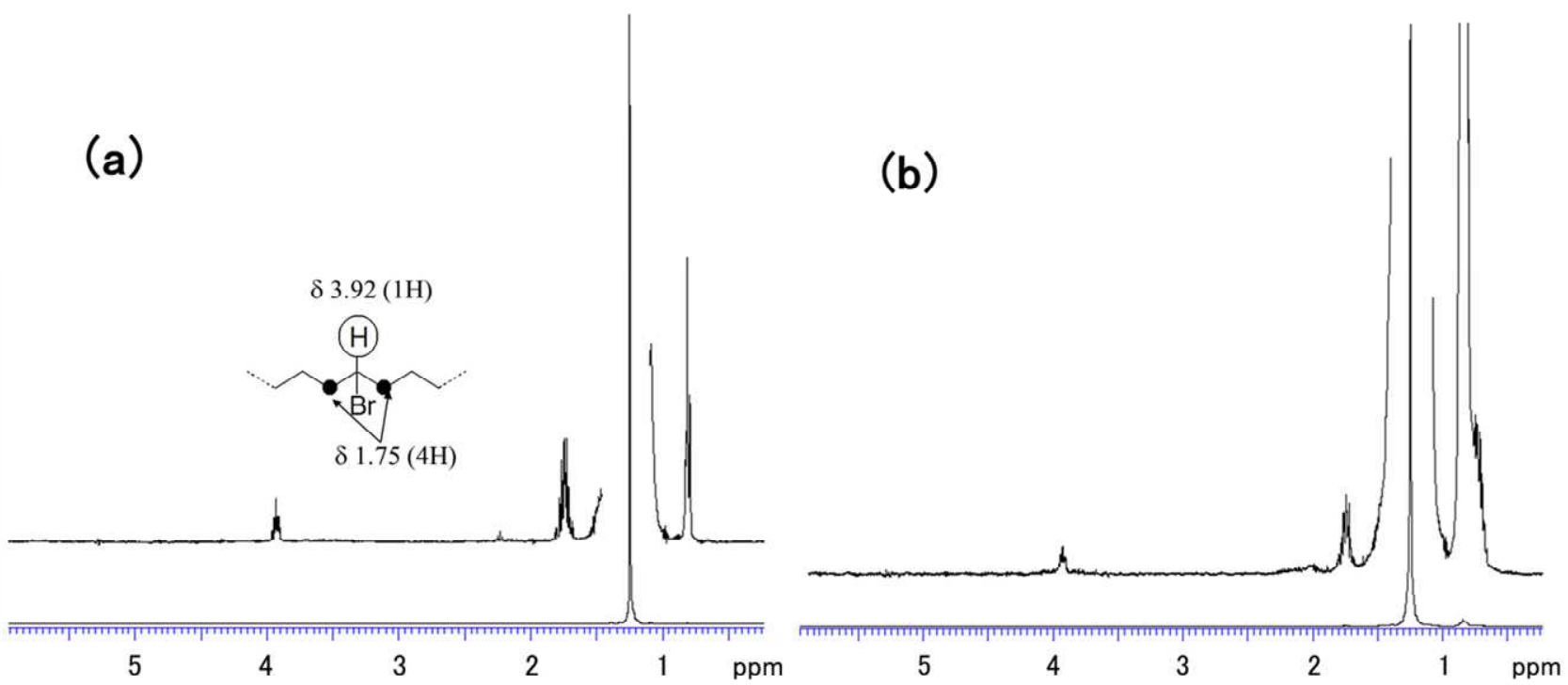

Fig.5 ${ }^{1}$ H NMR spectrum of (a) HDPE-Br (entry 8) and (b) LDPE-Br (entry 9)

The radical polymerization of methyl methacrylate (MMA) with a series of brominated polyolefins as a macroinitiator was performed using a $\mathrm{CuBr} / N, N, N$, $N$,',$N$ ' '-pentamethyldiethylenetriamine (PMDETA) catalyst system in $o$-xylene solution at $100{ }^{\circ} \mathrm{C}$. The viscosity of the polymerization mixture increased with increasing time, indicating the formation of the copolymer with higher molecular weight compared with the macroinitiator. In order to remove the PMMA homopolymer produced by a thermal polymerization as a side reaction, the obtained polymers were purified by Soxhlet extraction with boiling acetone. It was confirmed that these copolymers contained only a small amount (less than 5 wt.\%) of homopolymer. The polymerization results are shown in Table 2 . In all cases, $M_{\mathrm{n}}$ of the resulting polymers was larger than that for each brominated polyolefin.

Table 2 Polymerization of MMA with Brominated Polyolefins

\begin{tabular}{|c|c|c|c|c|c|c|c|c|c|c|c|}
\hline \multicolumn{3}{|c|}{ Brominated Polyolefins $^{\text {a) }}$} & \multirow{2}{*}{$\begin{array}{c}\mathrm{CuBr} \\
{[\mathrm{mmol}]}\end{array}$} & \multirow{2}{*}{$\begin{array}{l}\text { MMA } \\
{[\mathrm{ml}]}\end{array}$} & \multirow{2}{*}{$\begin{array}{c}o \text {-Xylene } \\
{[\mathrm{ml}]}\end{array}$} & \multirow{2}{*}{$\begin{array}{c}\text { Time }^{\mathrm{c})} \\
{[\mathrm{h}]}\end{array}$} & \multirow{2}{*}{$\begin{array}{c}\mathrm{SP}^{\mathrm{d})} \\
{[\mathrm{wt} . \%]}\end{array}$} & \multirow{2}{*}{$M_{\mathrm{n}}^{\mathrm{b})}$} & \multirow{2}{*}{$\mathrm{PDI}^{\mathrm{b})}$} & \multirow{2}{*}{$\begin{array}{c}\text { Content of MMA } \\
{[w t . \%]^{\mathrm{e})}}\end{array}$} & \multirow{2}{*}{$\begin{array}{c}T_{\mathrm{m}} \\
\left.\left[{ }^{\circ} \mathrm{C}\right]^{\mathrm{f}}\right)\end{array}$} \\
\hline & $M_{\mathrm{n}}^{\mathrm{b})}$ & {$[\mathrm{g}]$} & & & & & & & & & \\
\hline PP-Br (2) & 60.0 & 20 & 2.1 & 46 & 254 & 1 & 1.6 & 114.5 & 4.0 & 44.5 & 153.3 \\
\hline PMP-Br (5) & 73.2 & 15 & 1.6 & 40 & 260 & 1 & 0.4 & 80.9 & 4.3 & 28.3 & 225.4 \\
\hline $\mathrm{EP}-\mathrm{Br}(6)$ & 42.0 & 15 & 2.7 & 100 & 200 & 1 & 3.4 & 81.7 & 3.4 & 46.2 & 41.8 \\
\hline EB-Br (7) & 79.8 & 15 & 2.7 & 100 & 200 & 1 & 4.0 & 95.2 & 2.8 & 27.5 & 36.0 \\
\hline HDPE-Br (8) & 25.6 & 20 & 2.0 & 67 & 233 & 4 & 2.6 & 33.5 & 5.3 & 12.2 & 131.6 \\
\hline LDPE-Br (9) & 36.1 & 20 & 2.0 & 67 & 233 & 4 & 3.4 & 41.4 & 9.0 & 16.5 & 103.5 \\
\hline LLDPE-Br (10) & 49.3 & 20 & 2.0 & 67 & 233 & 4 & 3.4 & 59.0 & 2.9 & 12.2 & 116.9 \\
\hline
\end{tabular}


In addition, the contents of MMA were determined by ${ }^{1} \mathrm{H}$ NMR analysis of the purified copolymers. These results indicate the formation of the block or graft copolymers linked between polyolefin and PMMA segments.

It is well known that allylic halides can be employed as an initiator for the metal-catalyzed living radical polymerization of styrene ( $\mathrm{St}$ ) and MMA because the allyl radical is relatively stable due to the conjugation of a vinyl group with the carbon-centered radical.[21-22] Therefore, in these brominated polyolefins, the allylic bromide moieties should initiate the radical polymerization in the presence of a transition-metal catalyst, resulting in the polyolefin-based block and graft copolymers. In fact, the allylic bromide moieties have been consumed after the polymerization from ${ }^{1} \mathrm{H}$ NMR analysis, suggesting that the MMA polymerization initiated from these sites as shown in Figure 6. In the case of polyethylenes, however, there are few or no allylic bromide moieties but secondary bromide units in their backbone as mentioned above. ${ }^{1} \mathrm{H}$ NMR reveals that most of the secondary bromide unit remained even after polymerization and thereby its initiation efficiency was low. Alternatively, other brominated structures like a tertiary bromide, which are not detectable by ${ }^{1} \mathrm{H}$ NMR spectroscopy, might exist and act as an initiation site.

(a)

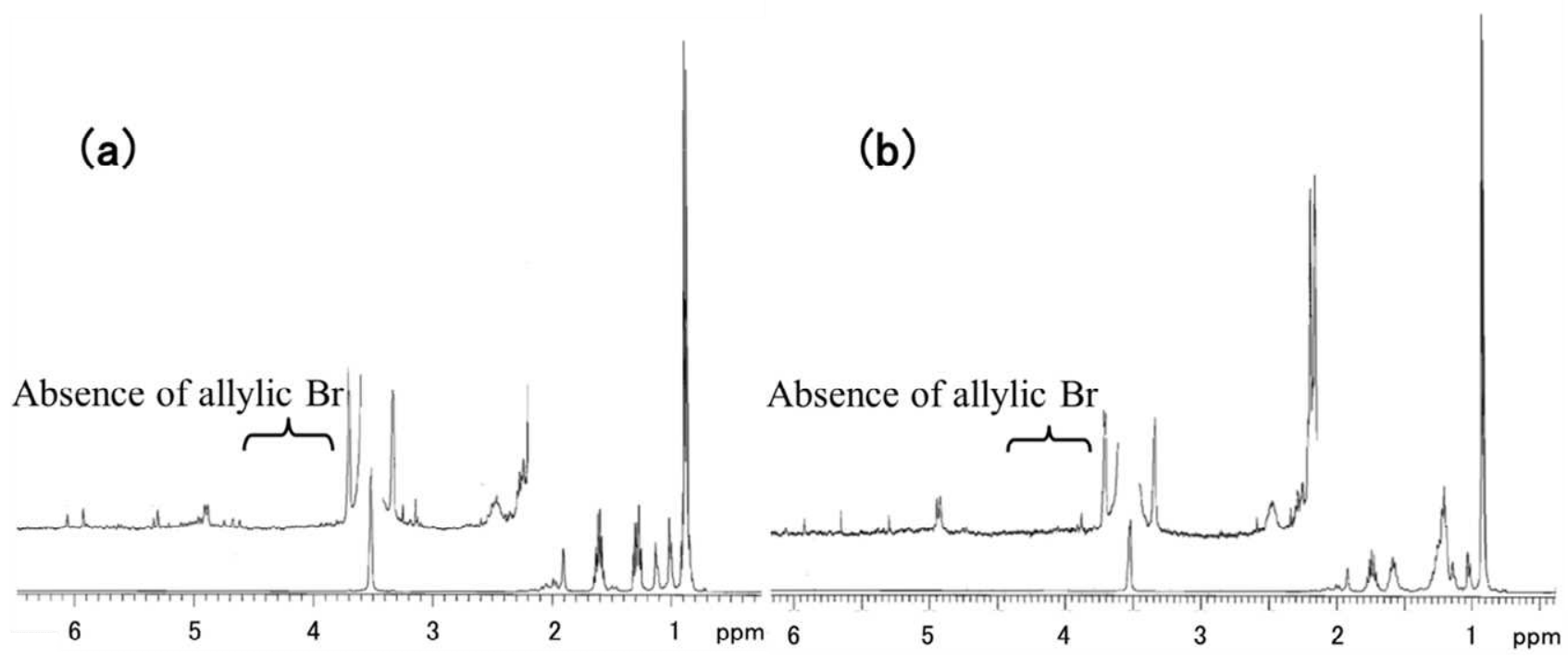

Fig.6 $\quad{ }^{1} \mathrm{H}$ NMR spectrum of (a) PP-PMMA copolymer and (b) PMP-PMMA copolymer 
Table 3 Radical Polymerization of Various Monomers with Brominated PP

\begin{tabular}{|c|c|c|c|c|c|c|c|c|c|c|c|}
\hline $\begin{array}{c}\text { PP-Br }(2)^{a)} \\
{[g]}\end{array}$ & $\begin{array}{l}\text { Monomer } \\
{[\mathrm{ml}]}\end{array}$ & $\begin{array}{c}\mathrm{CuBr} \\
{[\mathrm{mmol}]}\end{array}$ & $\begin{array}{c}o \text {-Xylene } \\
{[\mathrm{ml}]}\end{array}$ & $\begin{array}{c}\mathrm{T}^{\mathrm{b})} \\
{\left[{ }^{\circ} \mathrm{C}\right]}\end{array}$ & $\begin{array}{c}\operatorname{Time}^{\mathrm{c})} \\
{[\mathrm{h}]}\end{array}$ & $\begin{array}{l}\text { Yield }^{\mathrm{d})} \\
{[\mathrm{g}]}\end{array}$ & $\begin{array}{c}\mathrm{SP}^{\mathrm{e})} \\
{[\mathrm{wt} . \%]}\end{array}$ & $M_{\mathrm{n}}{ }^{\mathrm{f}}$ & $\mathrm{PDI}^{\mathrm{f}}$ & $\begin{array}{c}\text { Content of } \\
\text { polar segment } \\
\left.[\text { wt. \% }]^{g}\right)\end{array}$ & $\begin{array}{c}T_{\mathrm{m}} \\
{\left[{ }^{\circ} \mathrm{C}\right]^{\text {h) }}}\end{array}$ \\
\hline 15 & EA (54) & 1.6 & 246 & 110 & 4 & 21.2 & 6.3 & 132.8 & 4.1 & 28.8 & 154.8 \\
\hline 15 & $t \mathrm{BuA}(73)$ & 1.6 & 227 & 110 & 4 & 24.1 & 6.3 & 116.3 & 3.5 & 35.6 & 154.4 \\
\hline 10 & St $(50)$ & 5.0 & 100 & 100 & 2 & 16.9 & 0.6 & 131.3 & 5.3 & 41.3 & 151.7 \\
\hline 15 & DMAEA (76) & 1.6 & 224 & 110 & 4 & 17.4 & 3.0 & n.d. ${ }^{\text {h) }}$ & n.d. ${ }^{\text {h) }}$ & n.d. ${ }^{\text {h) }}$ & 153.3 \\
\hline
\end{tabular}

Table 3 summarizes the polymerization results of other monomers with the PP macroinitiator (Table 1, entry 2). In all cases, the progress of the polymerization was confirmed by the increase of the polymer yield and the amount of homopolymer was less than $10 \mathrm{wt} . \%$ from the Soxhlet extraction. In the polymerizations of ethyl acrylate (EA), $t$-butyl acrylate (tBA) and St, the $M_{\mathrm{n}}$ of the purified copolymers increased from $60 \mathrm{~K}$ to $133 \mathrm{~K}, 116 \mathrm{~K}$ and $131 \mathrm{~K}$, respectively, by the GPC measurement in $1,2-$ dichlorobenzene at $140{ }^{\circ} \mathrm{C}$. In addition, the content of these polar segments was determined to be 28.8 , 35.6 and 41.3 wt.\%, respectively. On the other hand, the GPC measurement and ${ }^{1} \mathrm{H}$ NMR analysis for the purified copolymer possessing poly(2-dimethylaminoethyl acrylate) (PDMAEA) segments were not possible because of the poor solubility in 1,2-dichlorobenzene. Conversely, this fact provides evidence for the linking between PP and PDMAEA segments.

\section{Conclusion}

In conclusion, the method described in Scheme 1 provides a simplified procedure of synthesizing the polyolefin macroinitiator and the subsequent preparation for polyolefin-based block and graft copolymer. The direct bromination of polyolefins using NBS predominantly generated the allylic bromide moieties via a radical mechanism and the obtained bromide moieties could initiate the controlled radical polymerization of MMA, EA, $t$ BA, St and DMAEA with high initiation efficiency to give the copolymers linking polyolefin and polar segments. Because of the accessible synthesis of 
polyolefin macroinitiators, this synthetic methodology is expected to result in the preparation of a wide range of polyolefin-based block and graft copolymers. Further studies are now in progress at our laboratories to establish the scope and mechanism of the bromination reaction and to develop a variety of copolymers with designed topologies and compositions for some promising new application fields.

\section{References}

1. Moad G (1999) The synthesis of polyolefin graft copolymers by reactive extrusion. Prog Polym Sci 24:81-142. doi: 10.1016/S0079-6700(98)00017-3

2. Rätzsch M, Arnold M, Borsig E, Bucka H, Reichelt N (2002) Radical reactions on polypropylene in the solid state. Prog Polym Sci, 27:1195-1282. doi: 10.1016/S00796700(02)00006-0

3. Yanjarappa M J, Sivaram S (2002) Recent developments in the synthesis of functional poly(olefin)s. Prog Polym Sci 27:1347-1398. doi: 10.1016/S0079-6700(02)00011-4

4. Schellekens M A J, Klumperman B, (2000) Synthesis of polyolefin block and graft copolymers. J Macromol Sci Rev Macromol Chem Phys C40:167-192.

5. Chung T C (2001) Synthesis of functional polyolefin copolymers with graft and block structures. Prog Polym Sci 27:39-85. doi: 10.1016/S0079-6700(01)00038-7

6. Dong J Y, Hu Y (2006) Design and synthesis of structurally well-defined functional polyolefins via transition metal-mediated olefin polymerization chemistry. Coord Chem Rev 250:47-65. doi: 10.1016/j.ccr.2005.05.008

7. Lopez R G, D’Agosto F, Boisson C (2007) Synthesis of well-defined polymer architectures by successive catalytic olefin polymerization and living/controlled polymerization reactions. Prog Polym Sci 32:419454. doi: 10.1016/j.progpolymsci.2007.01.004 
8. Kawahara N, Saito J, Matsuo S, Kaneko H, Matsugi T, Kashiwa N (2008) Polymer hybrids based on polyolefins - syntheses, structures, and properties. Adv Polym Sci 217:79-119. doi: $10.1007 / 12 \_2008 \_136$

9. Kamigaito M, Ando T, Sawamoto M (2001) Metal-catalyzed living radical polymerization. Chem Rev 101:3689-3746.

10. Matyjaszewski K, Xia J (2001) Atom Transfer Radical Polymerization. Chem Rev 101:29212990. doi: $10.1021 /$ cr940534g

11. Matsugi T, Kojoh S, Kawahara N, Matsuo S, Kaneko S, Kashiwa N (2003) Synthesis and morphology of polyethylene-block-poly(methyl methacrylate) through the combination of metallocene catalysis with living radical polymerization. J Polym Sci Part A: Polym Chem 41:3965-3973. doi: 10.1002/pola.10991

12. Inoue Y, Matyjaszewski K (2004) Preparation of polyethylene block copolymers by a combination of postmetallocene catalysis of ethylene polymerization and atom transfer radical polymerization. J Polym Sci Part A: Polym Chem 42:496-504. doi: 10.1002/pola.10876

13. Inoue Y, Matsugi T, Kashiwa N, Matyjaszewski K (2004) Graft Copolymers from Linear Polyethylene via Atom Transfer Radical Polymerization. Macromolecules 37:3651-3658. doi: $10.1021 / \mathrm{ma} 0359887$

14. Kaneko H, Matsuo S, Kawahara N, Saito J, Matsugi T, Kashiwa N (2007) Synthesis and mechanical properties of polypropylene-based polymer hybrids via controlled radical polymerization. Macromol Symp 260:9-14. doi: 10.1002/masy.200751402

15. Matyjaszewski K, Teodorescu M, Miller P J, Peterson M L (2000) Graft copolymers of polyethylene by atom transfer radical polymerization. J Polym Sci Part A: Polym Chem 38:2440-2448. DOI: 10.1002/1099-0518

16. Liu S, Sen A (2001) Synthesis of Novel Linear Polyethene-Based Graft Copolymers by Atom Transfer Radical Polymerization. Macromolecules 34:1529-1532. doi: 10.1021/ma001682d 
17. Hwu J M, Chang M J, Lin J C, Cheng H Y, Jiang G J (2005) Synthesis and application of functional polyethylene graft copolymers by atom transfer radical polymerization. J Organomet Chem 690:6300-6308. doi: 10.1016/j.jorganchem.2005.04.043

18. Cao C, Zou J, Dong J Y, Hu Y, Chung T C (2005) Synthesis of polypropylene graft copolymers by the combination of a polypropylene copolymer containing pendant vinylbenzene groups and atom transfer radical polymerization. J Polym Sci Part A: Polym Chem 43:429-437. doi: 10.1016/j.polymer.2008.08.032DOI:10.1002/pola.20509

19. Kaneko H, Saito J, Kawahara N, Matsuo S, Matsugi T, Kashiwa N (2008) Synthesis and characterization of polypropylene-based polymer hybrids linking poly(methyl methacrylate) and poly(2-hydroxyethyl methacrylate). Polymer 49:4576-4584.

20. Kaneko H, Saito J, Kawahara N, Matsuo S, Matsugi T, Kashiwa N (2009) Synthesis and characterization of polypropylene-based block copolymers possessing polar segments via controlled radical polymerization. J Polym Sci Part A: Polym Chem 47:812-823. doi:

10.1002/pola. 23198

21. Nakagawa Y, Matyjaszewski K (1998) Synthesis of well-defined allyl end-functionalized polystyrene by atom transfer radical polymerization with an allyl halide initiator. Polym J 30:138-141. doi: 10.1295/polymj.30.138

22. Jakubowski W, Tsarevsky N V, Higashihara T, Faust R, Matyjaszewski K (2008) Allyl Halide (Macro)initiators in ATRP: Synthesis of Block Copolymers with Polyisobutylene Segments. Macromolecules 41:2318-2323 DOI:10.1021/ma7027837 